\title{
Non-destructive Mapping of Organosulfur of Source Rocks Using Energy Dispersive Spectroscopy and Back Scatter Electron
}

\author{
David Jacobi and John Longo
}

\section{Aramco Americas - Houston Research Center, Houston, Texas, United States}

Pyrites influence on the sulfur concentration of kerogen in source rocks is important to understand because sulfur is a free radical that lowers the activation energy of kerogen that controls the rate of its transformation into hydrocarbons as the rock is buried [1]. Chemically, this transformation accompanies a loss of hydrogen relative to carbon, the rate of which often produces porosity in kerogen for the storage of hydrocarbons. However, analyzing organic porosity in relation to kerogen sulfur and the surrounding pyrite can be challenging as the rock generally is destroyed to analyze both mineral and elemental properties. The organosulfur of kerogen is routinely determined by bulk elemental analysis of isolated kerogen that is recovered from acid digested source rock, and then separated, for purity, using density liquid separation. The final organosulfur value is derived by mass balance where the iron measured is used to compute the amount of sulfur contributed by pyrite in the recovered kerogen, which is then subtracted from the total sulfur measured. This destructive analysis, however fails to spatially capture, pyrites influence on the organosulfur concentration of the organic matter. It is related to its former depositional environment, which is recorded in the mineralogy and organic matter composing the rock surface that can be investigated using two dimensional scanning electron microscopy (2D-SEM) images.

Presented, is a new non-destructive method developed to identify and map the sulfur content of kerogen in relation to pyrite using 2D-SEM images integrated with energy dispersive spectroscopy (EDS) and back scatter electron (BSE). This method builds upon the platform of a mineral mapping software that was previously designed to map and quantify the mineralogy and organic matter of source rocks at the nanoscale from 2D-SEM images using EDS and BSE [2]. The integration of elemental maps of iron, carbon, and sulfur from EDS along with BSE maps are used to map the sulfur content of the organic matter at the same nanoscale resolution using an elemental map subtraction algorithm.

The control of pyrite on the sulfur content of kerogen in source rocks can be traced back to microbial activity in ancient, anoxic, marine environments. As detrital sediment containing iron bearing minerals were deposited in marine bottom sediments, the iron released at the sediment-water interface, was scavenged by hydrogen sulfide generated from microbial sulfate reduction to produce pyrite [3] (Fig.1a). The accumulated organic matter in the bottom sediments provided a metabolic substrate for the microbes that controlled the rate of this sulfate reducing activity. This relationship can be seen in the mineral map of a carbonate source rock computed from EDS elemental and BSE maps that quantifies and maps the presence of framboidal pyrite (red) and the organic matter (black) within the rock (Fig.1b). The amount of pyrite that forms in carbonate sediments rich in calcite (blue) can be limited because appreciable amounts of iron bearing mineral detritus deposited in these types of environments are not normally abundant. As a result, the hydrogen sulfide generated from the sulfate reducing microbes is often not sequestered with pyrite, and instead is assimilated into the organic matter, the precursor of kerogen [4].

The corresponding $\mathrm{C}, \mathrm{Fe}$, and $\mathrm{S}$ elemental maps measured from the 2D-SEM image using EDS can be used to show the effects of this limited pyrite formation on the chemistry of the organic matter. The mineral map (Fig. 1b) shows pyrite as computed using the Fe and S elemental maps (Fig.1c, 2a) as being no more than $0.4 \%$. Moreover, the mineral map also shows clay minerals, such as illite (0.4\% -gray), a detrital iron source that contributes to the formation of pyrite, were minimal and the low quartz (yellow) content indicates there was a lack of clastic detritus within the sediments as well. The remaining $\mathrm{S}$ 
elemental intensities, apart from those associated with pyrite, also correlate with certain C elemental map intensities (Fig. 2 b). The higher intensities from the $\mathrm{C}$ map are related to the organic matter within the rock which is composed of a larger concentration of carbon than the lower intensity carbon from the calcite composing the mineral map. The higher intensities therefore in carbon, represented as the organic fraction, correlate with the higher intensities of the $S$ map, apart from the intensities from the sparse pyrite, suggesting organosulfur has accumulated in the organic matter as the result of the low concentration of pyrite in the sediments.

To define and map the organosulfur across the 2D-SEM image to quantify the concentration requires the removal of sulfur related to pyrite as it has the higher concentration of sulfur than that assimilated in the organic matter and therefore the highest intensity. This is accomplished by an algorithm that uses the Fe elemental intensity equal to the concentration of Fe in pyrite to subtract an intensity from sulfur equal to the concentration of sulfur in pyrite. This process produces a sulfur map of the organic matter, minus the sulfur of pyrite, that correlates and overlays with the higher intensities of the C elemental map (Fig. 2b). The organosulfur map shows former grains of pyrite, seen in the original S map, have disappeared as evidence of the subtraction (Fig. 2c). This non-destructive method for mapping organosulfur spatially can be used apart from the traditional destructive method described earlier for obtaining the value. The ability to map and quantify sulfur spatially in source rocks is key to understand the changes in activation energies and the hydrogen to carbon composition of kerogen that could influence its transformation into hydrocarbons.

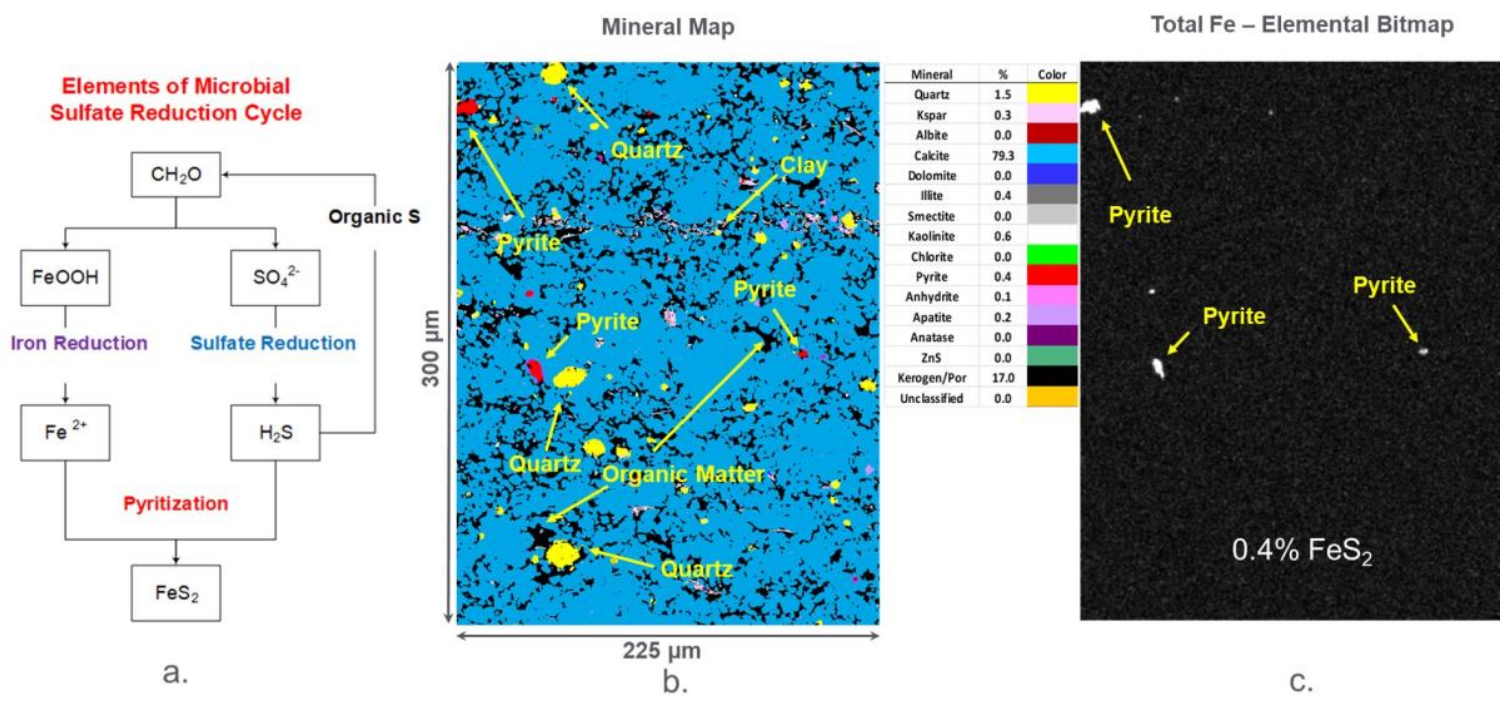

Figure 1. (a) Graphic showing the Microbial Sulfate Reduction Cycle (b) Mineral map of computed calcite, pyrite, clay and organic matter associated with the carbonate source rock (c) Fe elemental map showing intensity related to pyrite. 

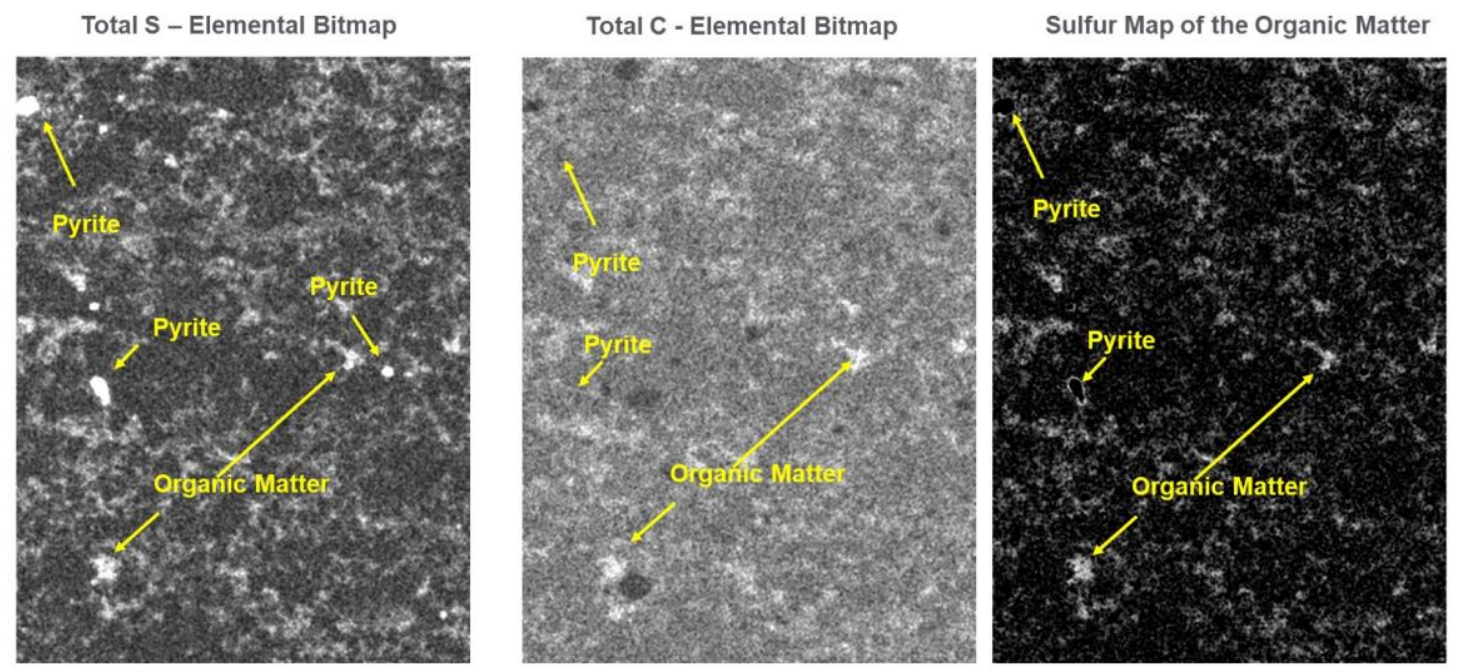

Pyrite sulfur subtracted using iron map to produce organic sulfur for carbon map a.

b.

C.

Figure 2. (a) Total sulfur elemental maps showing intensities related to pyrite and the organic matter (b) Total carbon elemental maps showing intensities related to carbonate as well as organic matter that correlates with the intensities of sulfur (c) Organosulfur map created using the Fe and S elemental map intensity subtraction method overlaying the $\mathrm{C}$ map intensity of the organic matter.

\section{References}

[1] Eglinton T.I., Damste Sinninghe J.S., Kohnen M.E.L, de Leeuw J.W., Larter, S.R. and Patience R.L.(1990) "Analysis of Maturity Related Change in the Organic Sulfur Composition of Kerogens by Flash Pyrolysis - Gas Chromatography" in Organic Sulfur in Macromolecular Sedimentary Organic Matter IV; American Chemical Society. pp 529-565.

[2] Jacobi D.J, Sun Q., Longo J., Brothers J., and Kone J., 2019 "Innovative Mapping of Mineral and Organic Matter of Source Rocks at the Nanometer Scale Using Back Scatter Electron and Energy Dispersive Spectroscopy". Microscopy and Microanalysis 25 (Suppl 2), pp. 2422-2423.

[3] Microbial Geochemistry, Blackwell Scientific Publications, ed. W.E Krumbein, Oxford, 1983.

[4] Hughes W.B., Holba A.G. and Dzou L.I.P. 1995 "The ratios of dibenzothiophene to phenanthrene and pristane and phytane as indicators of depositional environment and lithology of petroleum source rocks" Geochimica et Cosmochimica Acta, vol 59, No.17, pp. 3581-3598. 